\title{
The ERIC Clearinghouse for Junior College Information-An Innovation in Education
}

\begin{abstract}
Information systems are now a reality in the field of education. The ERIC system is the first major attempt, based upon public funds, to establish a nationwide network of information centers dealing with several disciplines in education. At the present time the Clearinghouse for Junior College Information is the first center to represent a particular level of education. By concentrating first upon the acquisition and dissemination of locally-produced reports of institutional research in junior colleges, this clearinghouse seeks to fulfill its function as an agency designed to classify and distribute information to a specialized field.
\end{abstract}

$\mathbf{I}_{\mathbf{N}}$

RECENT YEARS American education has been the beneficiary of widespread public interest and substantial financial support from both private and public sources. As a result, research efforts and programs of institutional development have mushroomed on all levels of education. Concurrently, the size of the body of research information being developed has expanded into seemingly limitless proportions. The problem of disseminating research methodologies and findings in order to avoid costly duplication and wasted effort and in order to translate research into practice has become crucial. In response to this need, the Educational Research Information Center has been developed by the United States Office of Education.

Dr. Mathies is Head, Education and Psychology Library, UCLA, and Co-Investigator, Clearinghouse for Junior College Information.

\section{The Educational Research INFORMATION CENTER}

The background of the Educational Research Information Center (ERIC) is found in the funding of the Cooperative Research Programs of the United States Office of Education in 1956. With this act, the scope of educational research programs based upon legislation enacted by Congress increased rapidly. As the body of reports grew, leaders in the federal government realized that the sponsorship of research was only a part of the responsibility of the U.S. Office of Education. Some way of sharing the results of these efforts had also to be developed. The first large-scale attempt to do so was made in 1965 when the Educational Research Information Center was established. The initial project undertaken by ERIC was in support of the Elementary and Secondary Education Act. At that time 1750 documents on the special educational needs of the disadvantaged were collected, indexed, ab- 
stracted, and sent to state and local education departments.

The general plan for the development of ERIC called for the establishment of a headquarters office in Washington, D.C., the organization of a decentralized network of clearinghouses designed to serve separate segments of education, and the development of a document reproduction service. At the present time thirteen clearinghouses have been established at various universities and research centers throughout the country. They cover such general areas as reading, which is located at Indiana University; educational administration, at the University of Oregon; vocational and technical education, at the Ohio State University; and junior colleges, at the University of California, Los Angeles. Five new clearinghouses have been funded recently, including one on libraries which will be located at the University of Minnesota. The location of these centers is in keeping with the ERIC policy of utilizing established collections and specialists at the site of their concentration.

The ERIC program is designed to become a nationwide information service for teachers, administrators, librarians, and researchers. Therefore ERIC is concerned with the acquisition of reports of basic and applied research as well as fugitive documents which report innovative ideas and emerging knowledge in each field. The location and dissemination of current unpublished research and research-related materials which have a low distribution is the essence of the ERIC project.

ERIC clearinghouses acquire, select, index, and abstract documents in their fields of interest. At each clearinghouse, a paper-tape typewriter is used to record document data uniformly on ERIC résumé report forms and punched paper tapes. Copies of the résumé forms, the paper tapes, and the documents are sent to Central ERIC where they become the principal devices for information storage and retrieval.

The Autonetics Division of North American Aviation at Anaheim, California, is the contracting agency with the responsibility for converting the data from paper tapes into a central computer system designed for rapid storage and retrieval. The résumé forms, which include abstracts, and the actual documents are photographed and made available to the consumer either on hard copy (paper) or microfiche form through the Educational Document Reproduction Service-a unit of the Bell and Howell Corporation in Cleveland, Ohio.

Research in Education, a monthly publication of the U.S. Office of Education, includes announcements of new projects funded by the Office of Education and reports of recently completed studies. Abstracts of documents processed by the clearinghouses appeared for the first time in the July 1967 issue. In addition to bibliographic information and abstracts, each issue provides prices and procedures for ordering copies of reports.

The ultimate goal of ERIC is to develop a network that will link universities, professional organizations, school systems, and boards of education so that research results may speedily be sent to places where and when they are needed. The Clearinghouse for Junior College Information is one unit of this network.

\section{Clearinghouse for Junior College INFORMATION}

The development of two year colleges from eight institutions with a total of 100 students at the beginning of the century to 837 junior colleges enrolling nearly 1.5 million students in 1966 is phenomenal. ${ }^{1}$ Reports in 1966 show that fifty-two

1 Junior College Directory, 1967 (Washington, D.C. American Association of Junior Colleges, 1967), p. 6. 
newly established junior colleges enrolled 53,234 students in their first semester of operation." "It has been estimated that by 1970 there will be 1,000 junior colleges enrolling nearly two million students."3

The tremendous impact of these institutions and their students upon the structure of American education is obvious. More than that, the commitment of junior college educators to give quality education while maintaining the "open door" policy means that each institution must bear close examination and evaluationif it is to continue to render such services. As do institutions of other kinds, junior colleges have their deficiencies and problems.

Much of this examination must come from within each institution. When it is formalized, such efforts are known as "institutional research." Institutional research is defined in many ways. A particularly appropriate definition is that designated by Hendrix as "any study, formal or informal, made on the campus of any part of the college, its program, or its operation by any group or individual." Brumbaugh emphasized the importance of institutional research in the following statement:

The key to effective administration is the ability of the president and those who work with him to ask the right questions and then to find the right answers. But the right answers to the right questions, whether they are specific in relation to a given institution or whether they are more comprehensive, must take into account all the relevant, factual data-the kind of data that only institutional research can provide. ${ }^{5}$

\footnotetext{
2 "Junior College Growth," Junior College Journal, XXXVII (April 1967), 7.

3 Junior College Directory, loc. cit.

4Vernon Hendrix, "Institutional Research in Junior Colleges." Paper presented at National Institutional Research Forum, May 18, 1964. mimeo., p. 4.

${ }^{5}$ A. J. Brumbaugh. Research Designed to Improve Institutions of Higher Learning (Washington, D.C., American Council on Education, 1960), p. 2.
}

In March 1966, a proposal for funds to establish a clearinghouse on community colleges at UCLA was submitted to the Bureau of Research of the U.S. Office of Education. This center would be one of twelve decentralized units in a network of information centers which were being organized throughout the nation in association with the Educational Research Information Center in Washington, D.C. At UCLA this new concept of information handling in education is of mutual interest to the graduate school of education, the school of library service, the institute of library research, and the university libraries. Much of the groundwork for this project was laid in the Junior College Leadership Program sponsored by the Kellogg Foundation, and in the Medical Literature Analysis and Retrieval System (MEDLARS), and the Brain Information Service projects of the university biomedical library. These facts, coupled with national leadership in the field at the university and the strong concentration of junior colleges in California, made the university an appropriate site for this clearinghouse. Late in May the proposal was funded at $\$ 108,731$ for the contract year-June 1 , 1966 through May 31, 1967.

The Clearinghouse for Junior College Information was established at UCLA as a joint project of the graduate school of education and the education and psychology library. The principal investigator and the co-investigator of the proposal assumed the roles of director and associate director respectively. Located in the Powell library building, professional staffing appointments include an associate director, an information specialist, a junior college specialist, a systems specialist, and a librarian (III) who acts as head of the indexing-abstracting section, as well as appropriate supporting personnel.

In accordance with a requirement of the ERIC program, an advisory board 
has been formed which is composed of eminent leaders in the junior college field, both statewide and nationally; the university librarian; and the director of the institute of library research. The principal functions of the Advisory Board are to approve criteria for controlling the quality of input to the clearinghouse collection, to determine ways of improving user service on a demand retrieval basis, and to give guidance to the over-all direction of the clearinghouse operations.

The clearinghouse performs several distinct functions. It acquires, abstracts, indexes, stores, retrieves, and disseminates the most significant and timely research and research-related documents relevant to public and private community and junior colleges. This includes studies concerned with junior college students, staff, curricula, programs, libraries, community services, and any other subject specifically related to the development and evaluation of junior college operations.

The clearinghouse has, for the most part to date, collected fugitive research studies. "Fugitive" indicates that the study has not yet been published or widely disseminated. Reports of institutional research are the most common types of fugitive material. Surveys, conference proceedings, and certain committee reports are also representative of such materials. Certain monographic publications and journal articles will also be included in the clearinghouse collections. Dissertations and theses relating to junior colleges and their programs are another valuable source of clearinghouse information.

Input quality is also a significant aspect of the ERIC program. Such factors as format, originality, relevance, and technical quality are essential qualifications. Limitations in the size and scope of Research in Education make it necessary for clearinghouses to devise other ways of reporting their collections to the field. Junior College Research Review, the initial publication of this clearinghouse, reports state-of-the-art papers and bibliographies based upon documents in the clearinghouse collection. Abstracts or copies of documents in this collection are available upon request.

All documents worthy of retention are indexed and abstracted according to specifications received from Central ERIC. A system of coordinate indexing is used for analyzing the subject content of the materials. Basically, this system depends upon the assignment of a number of terms or concepts to each document entered into the system. These terms, called descriptors in the ERIC system, are technically meaningful terms or subject headings which, when taken together, describe a document and may be used as index entries. Descriptors provide a dual function. They permit the indexer to describe the subject elements of the document so that it may be stored in a system and later searched for retrieval. They also provide the material from which a question may be constructed for the system to answer. The descriptors then comprise the indexing vocabulary. The size of the vocabulary and its range of specificity have a marked effect upon the form of the index and upon its bulk.

The control of terminology in the ERIC project is maintained by the use of a Thesaurus of ERIC Descriptors. The first edition of the Thesaurus was a product derived from the processing of 1750 documents relating to the disadvantaged children at preschool, elementary, and secondary school levels. The fact that the original thesaurus reflected a specific subject area at specific levels of interest was recognized as a limitation in its general usefulness. A revised edition has been developed, and procedures for frequent up-dating of the Thesaurus have been established. 
When the cataloging, indexing, and abstracting have been completed, the document citation, abstract, and index terms are recorded on a standard ERIC résumé form via a paper-tape typewriter. The documents, résumé forms, and punched paper tapes are sent to Central ERIC where they become the principal vehicles for storage, retrieval, and dissemination.

Reference and retrieval services are the newest aspects of the clearinghouse operation at this time. Inquiries include requests for searches on such specific topics as the evaluation of particular programs, data on transfer students, studies of teacher load in junior colleges, reports on vocational and technical curricula, studies of attrition rates, and requests concerning architectural designs and master plans.

Since most requests are received by mail, the procedure is to translate the requests into the language of the index system and thus formulate the initial search strategy. The index or inverted file provides access to each document in the collection through the clearinghouse accession number. A complete citation can be obtained from the shelflist and direct access to the document will also provide an abstract of the report. Ab- stracts of documents or full copies on microfiche are furnished to users on request.

Various types of services are anticipated for the Clearinghouse for Junior College Information. Immediate access to the collection now results in reference and retrieval services which provide bibliographies, abstracts, and periodic state-of-the-art reports produced in a periodical. Extended efforts may result in the preparation of "packages" of bibliographies or special interpretive reports. This would be done in anticipation of the requirements of users who wish to be alerted to new developments and also to accommodate a number of potentially repetitive requests. The operation of a program or workshop for users of an information retrieval system would also be appropriate.

As a unit of the ERIC system, the Clearinghouse for Junior College Information seeks to meet the information needs of all junior college educators-librarians, administrators, teachers, counselors, and others. In a large measure, its success will depend upon the development of relationships with all junior college personnel. Communication and cooperation are the essence of this activity.

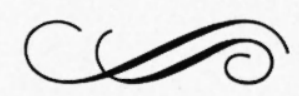

